\title{
Seasonal Fluctuations in Brain Nuclei in the Red-sided Garter Snake and Their Hormonal Control
}

\author{
David Crews, Rebecca Robker, and Mary Mendonça ${ }^{a}$ \\ Departments of Zoology and Psychology and the Inslitute of Reproductive Biology, The University of Texas at Austin, \\ Austin, Texas 78712
}

In many vertebrates, breeding seasons are protracted and mating behavior is temporally associated with gonadal growth and increased sex steroid hormone secretion. In the redsided garter snake (Thamnophis sirtalis parietalis), mating behavior is restricted to the 2-4 weeks immediately following emergence from winter dormancy. During this period mating behavior is sex-specific: chin-rubbing is exhibited only by males and receptivity to chin-rubbing is exhibited only by females. It is remarkable that mating occurs when the gonads are small and circulating concentrations of gonadal hormones are low. As in other vertebrate species, limbic nuclei are involved in the mediation of mating behaviors. To determine if limbic nuclei are sexually dimorphic and, further, whether they fluctuate in size with the seasons, the volume of brain areas was measured in both sexes at different times of the year (spring, fall, hibernation) and after hormone manipulation (gonadectomy and gonadectomy plus hormone treatment). The areas of interest were the preoptic area (POA), ventromedial hypothalamus (VMH), and the nucleus sphericus (NS or amygdala); control areas included the external nucleus of the optic tract (a cell-rich area) and medial forebrain bundle (a fiber-rich area). Comparisons according to season and manipulation revealed only two instances of sexual dimorphism: the POA of females was significantly smaller than that of males during hibernation and the NS of females was significantly smaller than that of males in those animals not subjected to hibernation. This general lack of sexual dimorphisms in the brain despite the sex-specificity of the behavior patterns and their marked seasonality may reflect the dissociated reproductive pattern characteristic of this species. In males, there was no statistical difference in the size of the brain areas when compared either by season or by hormonal manipulation. In females, on the other hand, there were significant seasonal fluctuations in both the POA and the VMH. Estrogen manipulation induced significant changes in a manner that paralleled the seasonal fluctuations in size. This sex difference in the seasonal variation

\footnotetext{
Received Jan. 25, 1993; revised June 18, 1993; accepted June 24, 1993.

We thank M. Shoesmith and W. Koonz of the Manitoba Department of Natural Sciences for their assistance in this research. We also thank Juli Wade and Walter Wilczynski for comments on the manuscript. D.C. was supported by NIMH Research Scientist Award 00135, and M.M., by NIMH NRSA MH09831.

Correspondence should addressed to David Crews, Department of Zoology, The University of Texas at Austin, Austin, TX 78712.

aPresent address: Department of Zoology, Auburn University, Auburn, AL 36830.

Copyright (c) 1993 Society for Neuruscience $0270-6474 / 93 / 135356-09 \$ 05.00 / 0$
}

in brain area size may be due to the fact that in the male, courtship behavior is androgen independent, whereas in the female, sexual receptivity is estrogen dependent.

IKey words: steroid hormones, brain nuclei, seasonal differences, sex differences, reptlle, snake, preoptic area, ventromedial hypothalamus, nucleus sphericus, amygdala, medial forebrain bundle]

A principle in vertebrate behavioral endocrinology is that reproductive behaviors are activated by steroid hormones (Crews and Silver, 1985). Removal of the gonads abolishes sexual behaviors, whereas hormone replacement therapy can reinstate sexual behaviors in gonadectomized animals. A principle in vertebrate neuroethology is that limbic nuclei play a pivotal role in the regulation of species-typical behaviors (Ingle and Crews, 1985). Areas such as the preoptic area (POA), ventromedial hypothalamus (VMH), and the amygdala are important integrative areas for sensory and motor events associated with innate behaviors. In many vertebrates these limbic nuclei, as well as other brain areas, are sexually dimorphic in size and fluctuate in volume with reproductive condition (reviewed in Kelley, 1988). The hormone dependence of these brain nucleus size changes has been reported in gerbils (Ulibarri and Yahr, 1988), Japanese quail (Panzica et al., 1991), rats (Dohler et al., 1984; Bloch and Gorski, 1988), ferrets (Tobet et al., 1986), and whiptail lizards (Wade et al., 1993).

These generalities are based on studies of species wherein sexual behavior is coincident with the increased levels of steroid hormones secreted by the active gonad (an associated reproductive pattern) (Crcws, 1984). However, somc vertebrates exhibit alternative reproductive patterns. For example, in the redsided garter snake (Thamnophis sirtalis parietalis), courtship behavior is restricted to the weeks immediately following emergence from winter hibernation (Fig. 1), a time when the gonads are small and circulating concentrations of steroid hormone are low. Male courtship behavior is not activated by gonadal androgens in the spring but by the increase in temperature following the prolonged low-temperature dormancy (Crews, 1983, 1990). Instead, androgen produced during the testicular recrudescence of the previous summer organizes the brain in such a manner that males will avidly court females after they emerge in the following spring (Crews, 1991).

What is known of the neural control of sexual behavior in garter snakes? To date only the male has been studied in this regard. Male courtship behavior is a chemosensory behavior. The flicking tongue of the male picks up pheromone molecules 

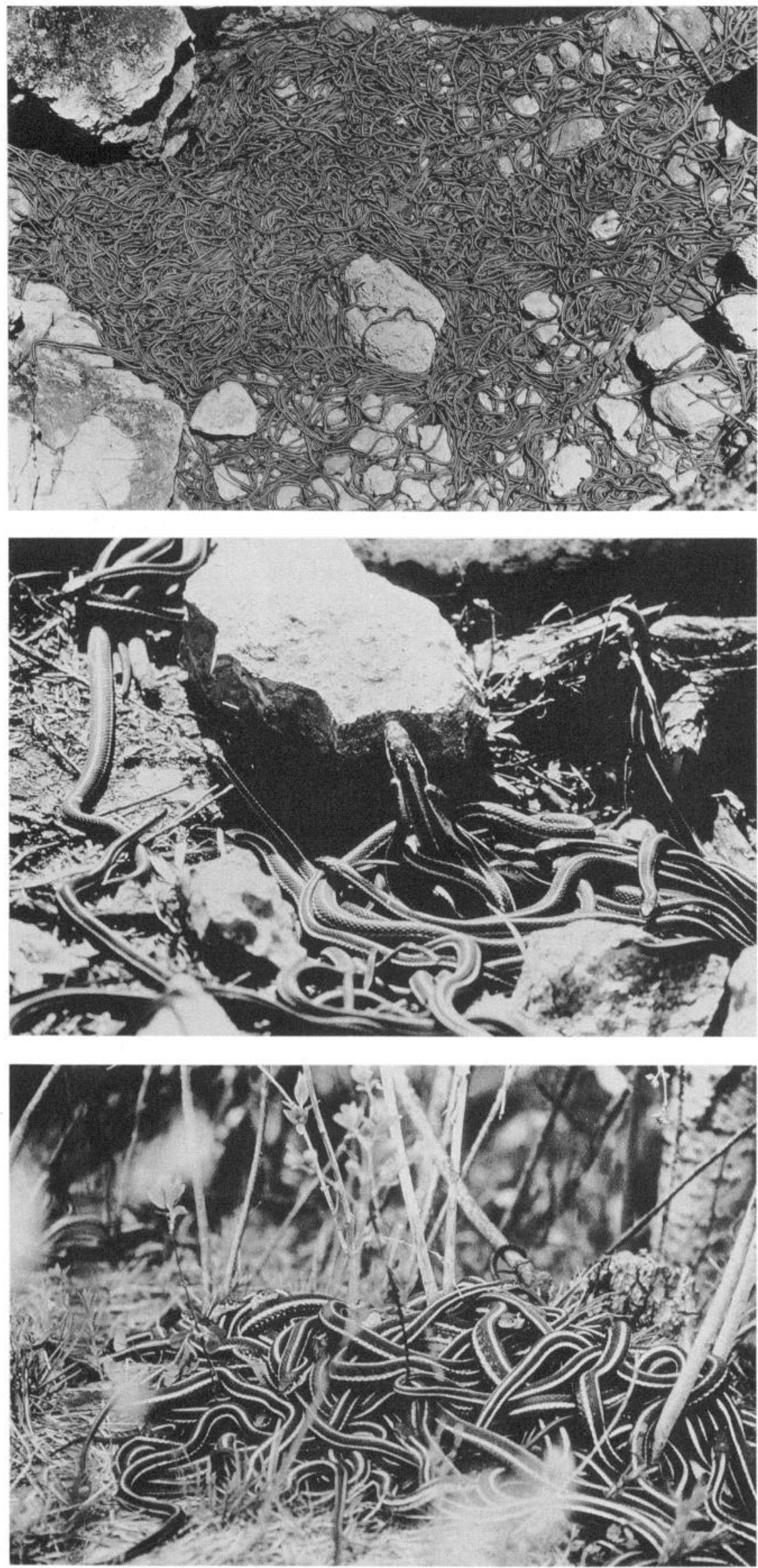

Figure 1. During most of the warm summer months, the Canadian red-sided garter snake leads a solitary existence. At two times of the year, spring and fall, however, the animals mass together. It is at these times the snakes emerge from, or later return to, underground overwintering hibernacula. Only during the spring is the intense mating activity observed. The top panel shows the density of males at a den entrance. All males emerge together and await the solitary emergence of females over the next $2-4$ weeks. The middle panel shows a female as she emerges from the underground hibernaculum. The males are attracted to a specific pheromone produced normally by females. The bottom panel shows the resulting "mating ball" that results. Only a single female will be at the center of this writhing mass of snakes. 
from the back of the female (Noble, 1937; Mason et al., 1989), and these pheromones are transported to the vomeronasal organ, where they are detected by the accessory olfactory bulb (Halpern, 1992). The accessory olfactory bulb sends its main projection to the nucleus sphericus (NS) (the reptilian homolog to the mammalian amygdala), which, in turn, projects in part to the POA and the VMH. The medial forebrain bundle (MFB) carries the efferents of the POA and NS as well as all ascending and descending fibers between the forebrain and the midbrain limbic areas, including the tegmental reticular formation.

Destruction of the POA by electrolytic lesion abolishes courtship behavior in males. This occurs whether POA lesions are produced in the spring in courting males (Friedman and Crews, 1985) or in the fall before the males enter hibernation (Krohmer and Crews, 1987a). It is perhaps significant that POA lesions also induce deficits in behavioral thermoregulation (Krohmer and Crews, 1987a). Lesion of the NS, on the other hand, facilitates courtship behavior (Krohmer and Crews, 1987b), suggesting that the POA is under inhibitory control of the NS. Using 2-deoxyglucose to monitor patterns of neural activity in the brain, Allen and Crews (1992) found that the POA and the NS in courting males were more active than in noncourting males.

As in the male, sex steroid hormone levels in the female are low at the time of mating. Mating triggers a neuroendocrine reflex that causes an immediate increase in circulating levels of prostaglandins (Whittier and Crews, 1989) followed by a surge in estradiol (Halpern et al., 1982; Garstka et al., 1985; Whittier and Crews, 1986; Whittier et al., 1987a; Mendonça and Crews, 1990a). In addition to stimulating hormone secretion, mating also causes the female to rapidly become unattractive and lose her receptivity (Ross and Crews, 1977, 1978; Whittier and Crews, 1989; Mendonça and Crews, 1990a). Unlike the male, gonadectomized females normally will not exhibit sexual behavior on emergence, but administration of estradiol immediately prior to emergence will reinstate receptivity (Mendonça and Crews, 1990b).

In both sexes, mating depends absolutely upon a long hibernation period and occurs at a time when circulating concentrations of steroid hormones are low (Halpert et al., 1982; Bona Gallo and Licht, 1983; Whittier and Crews, 1990). However, males and females appear to have differing neuroendocrine mechanisms controlling the expression of sexual behavior: in males, courtship is androgen-independent while in females, receptivity is estrogen-dependent. Behaviors also appear to be rigidly sex- and hormone-specific. Administration of androgen to ovariectomized females does not elicit the male-typical chinrubbing behavior (D. Crews, unpublished observations). Similarly, castrate males given estrogen are neither attractive nor receptive (Garstka et al., 1982; Crews, unpublished observations).

The question becomes "are there accompanying brain nucleus size changes that reflect both the seasonal constraint and the apparent differences in behavioral activation mechanisms?" The goals of this study, therefore, were threefold: (1) to determine if certain brain nuclei are sexually dimorphic, (2) to determine if there are seasonal fluctuations in the size of these brain nuclei in the male and female red-sided garter snake, and (3) to investigate what role, if any, gonadal steroid hormones might play in the determination of these differences. The findings are interpreted in terms of alternative neuroendocrine mechanisms regulating sexual behavior in a species with a dissociated reproductive pattern (Crews, 1984).

\section{Materials and Methods}

Animals. All animals were adult red-sided garter snakes collected at various times of the year in the Interlake region of Manitoba, Canada. Some snakes were killed upon collection; others were maintained in the laboratory under regimens that simulated natural environmental conditions. Some of the captive individuals were also hormonally manipulated.

Housing and maintenance. On return to the laboratory, snakes were separated by sex and housed in 30 gallon aquaria. They were kept at approximately $24^{\circ} \mathrm{C}$ and a $12: 12 \mathrm{hr}$ light/dark cycle (L/D) when not in hibernation. Animals were given water ad libitum and fed ground fish (frozen and canned) supplemented with vitamins twice a week. To simulate hibernation, some snakes were exposed to $4^{\circ} \mathrm{C}$ for 17 weeks from October to February. Prior to entering hibernation snakes experienced a 4 week period in which temperature and photoperiod were lowered in a step fashion; 2 weeks at $17^{\circ} \mathrm{C}$ and $10: 14 \mathrm{hr} \mathrm{L} / \mathrm{D}$ and 2 weeks at $10^{\circ} \mathrm{C}$ and $8: 16 \mathrm{hr} \mathrm{L} / \mathrm{D}$ to mimic the change in ambient conditions in Manitoba in the autumn.

Behavioral tests. In all instances, the behavior of the laboratory-housed, hormonally manipulated animals was monitored in standardized tests for sexual behavior to enable subsequent comparisons with the measurements of size of brain. Each individual was tested daily for 2 weeks; details of these tests are provided in Crews (1991) and Whittier et al. (1985). Briefly, a courting male will course up and down the female's back rapidly and repeatedly. This is called chin-rubbing. He will then align his vent with the female's vent (males are on average one-third the size of females). If the female is receptive, she will lift her tail and gape the cloaca; nonreceptive females are not forcibly mated. Animals collected in the field during the spring emergence were engaged in sexual activity.

Seasonal study. To determine whether the volume of specific brain nuclei fluctuated seasonally, animals were killed in the field in the spring of 1989 and 1990 (SPRING; total $n=20$ males, 12 females) and the fall of 1989 (FALL; $n=9$ males, 5 females). In both springs, males were collected at random around the periphery of the hibernaculum whereas the females were obtained as they emerged, one at a time, from the den. Statistical analyses of the whole brain and nuclei volumes of the two groups of SPRING animals of each sex determined that they did not differ significantly in any respect and thus were grouped by sex for further analysis [two-sided Student's $t$ test, $p$ values for females/ males: POA, 0.30/0.12; VMH, 0.89/0.42; NS, 0.34/0.17; external nucleus of the optic tract (ENOT), 0.46/0.82; MFB, 0.23/0.34; whole brain, $0.60 / 0.50]$. In the fall, both males and females were captured as they returned to the same den where they would overwinter. Additional animals collected in the field in the fall of 1989 were returned to the laboratory, where they were exposed to environmental conditions that mimicked what they would have experienced in the field. Animals undergoing hibernation in the laboratory were killed midway through hibernation (HIB; $n=5$ males, 8 females). During this same period, another group of animals were maintained in the laboratory at room temperature $\left(24^{\circ} \mathrm{C}\right)$ and did not undergo low-temperature dormancy (NOHIB; $n=6$ males, 7 females).

Hormonal manipulation study. Males and females either had their gonads removed or received a sham operation. Some of the gonadectomized individuals also received hormone treatment. All surgery was conducted under Brevital anesthesia $(1.5 \mathrm{mg} / \mathrm{kg}$ body weight) as described in Crews (1991) and (Mendonça and Crews, 1993).

The males were derived from a previously described experiment (Crews, 1991). These animals had been castrated in the fall of 1986 and then maintained for 5 years in the laboratory. During this period animals were exposed to a cycle of environmental conditions that simulated the annual cycle, including the 17 week low-temperature dormancy. On emergence each year they were tested for courtship behavior. Some males received a sham operation but remained intact (SHAM; $n=4$ males). In the final year, some long-term castrates received a Silastic capsule containing testosterone (CASTRATE $+\mathrm{T} ; n=4$ ) or an empty Silastic capsule (CASTRATE; $n=6$ ) for 6 weeks, during the preceding summer 7 months earlier. More specific information on these animals can be found in Crews (1991).

The females were derived from another previously described experiment (Mendonça and Crews, 1993). Females were ovariectomized in either the spring $(n-8)$ or the fall $(n=5)$ and maintained in the laboratory before being hibernated; these snakes were then killed 2 months after emergence from laboratory hibernation (equivalent to summer). Subsequent statistical analyses of the brain nuclei and brain 
Preoptic Area

Fall
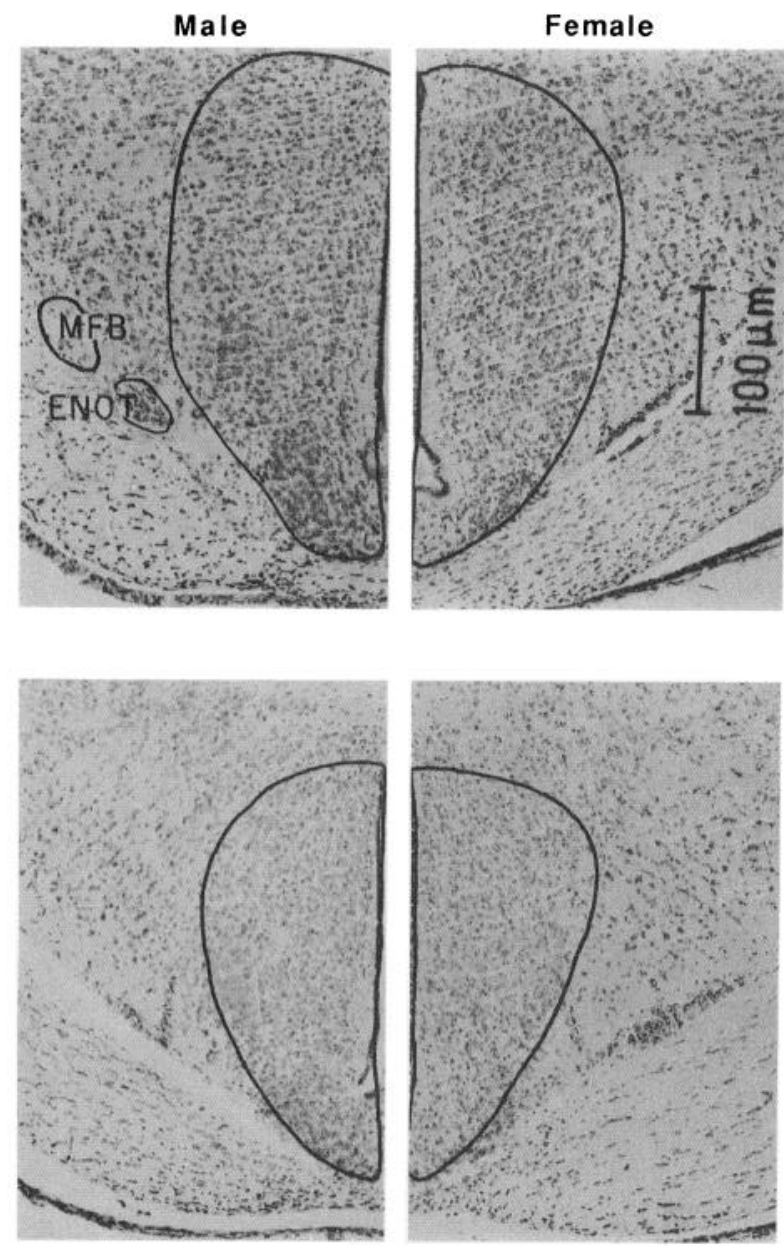

HIB

\section{Spring}
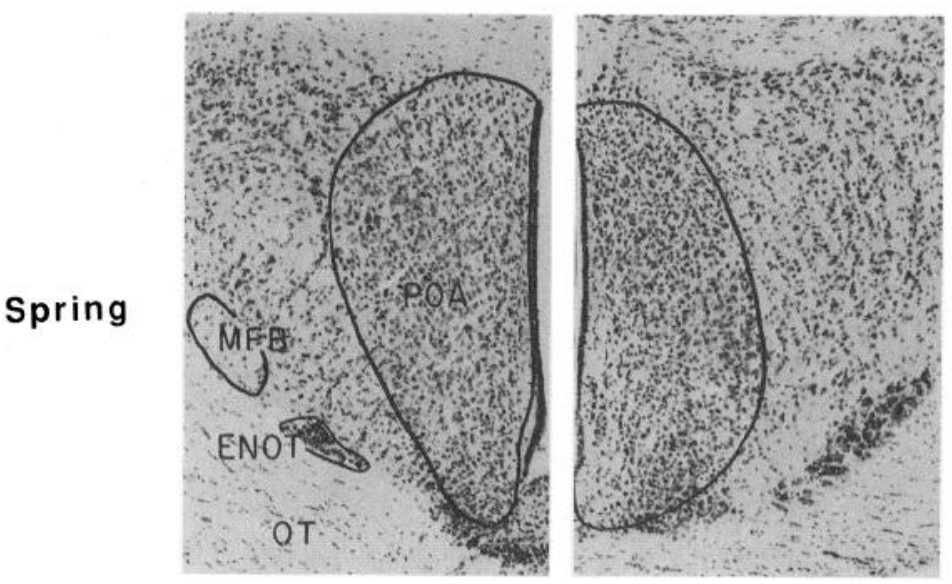
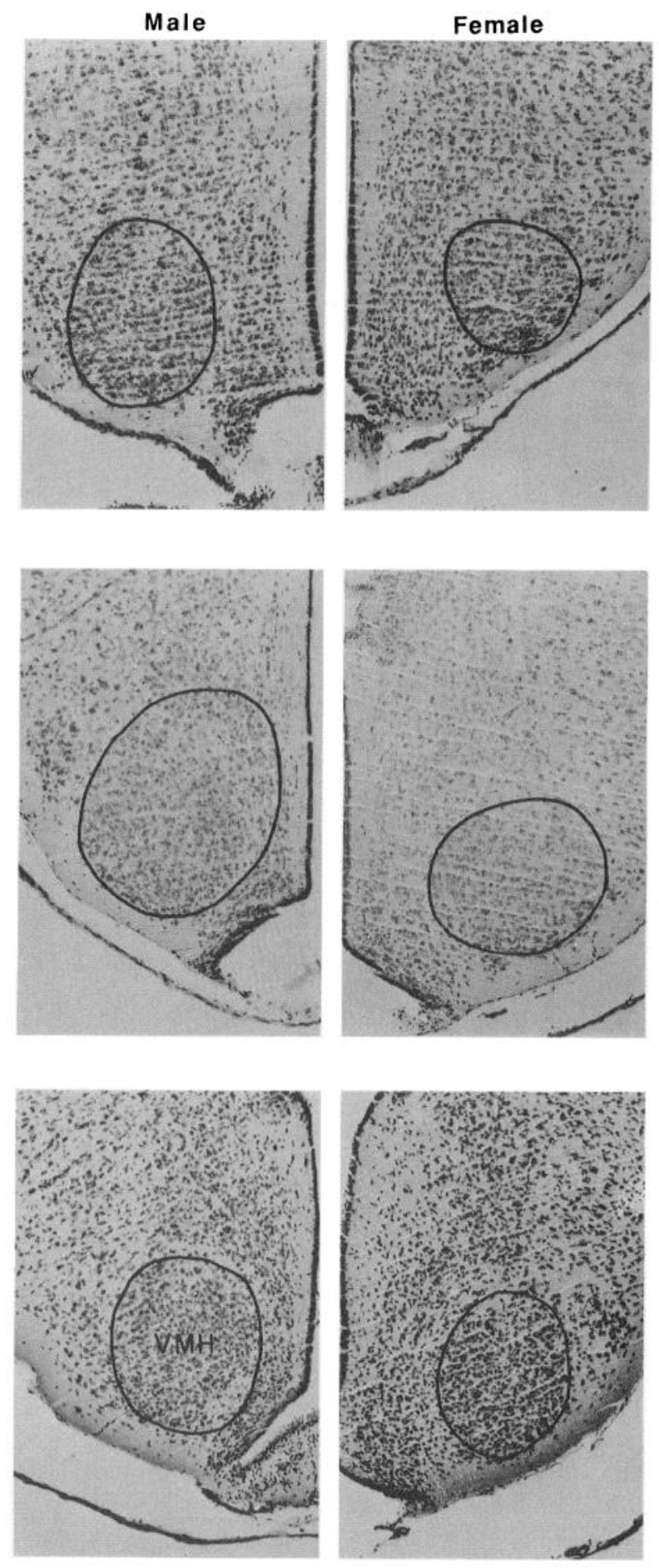

Figure 2. Brain areas measured in the red-sided garter snake (Thamnophis sirtalis parietalis). Shown are representative sections with the regions of interest outlined by the observer. Brains were from animals killed before entering hibernation $($ Fall $)$, during hibernation $(H I B)$, and on emergence from hibernation (Spring). In each panel, the male is on the left and the female is on the right. Areas measured are outlined. POA, preoptic area; $E N O T$, external nucleus of the optic tract; $V M H$, ventromedial hypothalamus; $M F B$, medial forebrain bundle; $O T$, optic tract.

area measurements of these two groups revealed no statistically significant difference between them (e.g., whole brain volume, $t=0.831, p$ $=0.42 ; \mathrm{POA}$ volume, $t=-0.008, p=0.99 ; \mathrm{VMH}$ volume, $t=1.58$, $p=0.143$; NS volume, $t=-0.157, p=0.88$ ). Therefore, they were combined into a single OVEX group $(n=13)$ for additional analyses.
Additional females were ovariectomized in the fall and hibernated in the same manner as the animals used in the seasonal analysis. Upon emergence, one group of these animals received a single injection of 20 $\mu \mathrm{g}$ of estradiol-17b (OVEX $+\mathrm{E} ; n=4)$ while the other group received an injection of vehicle only (SHAM; $n=3$ ). 


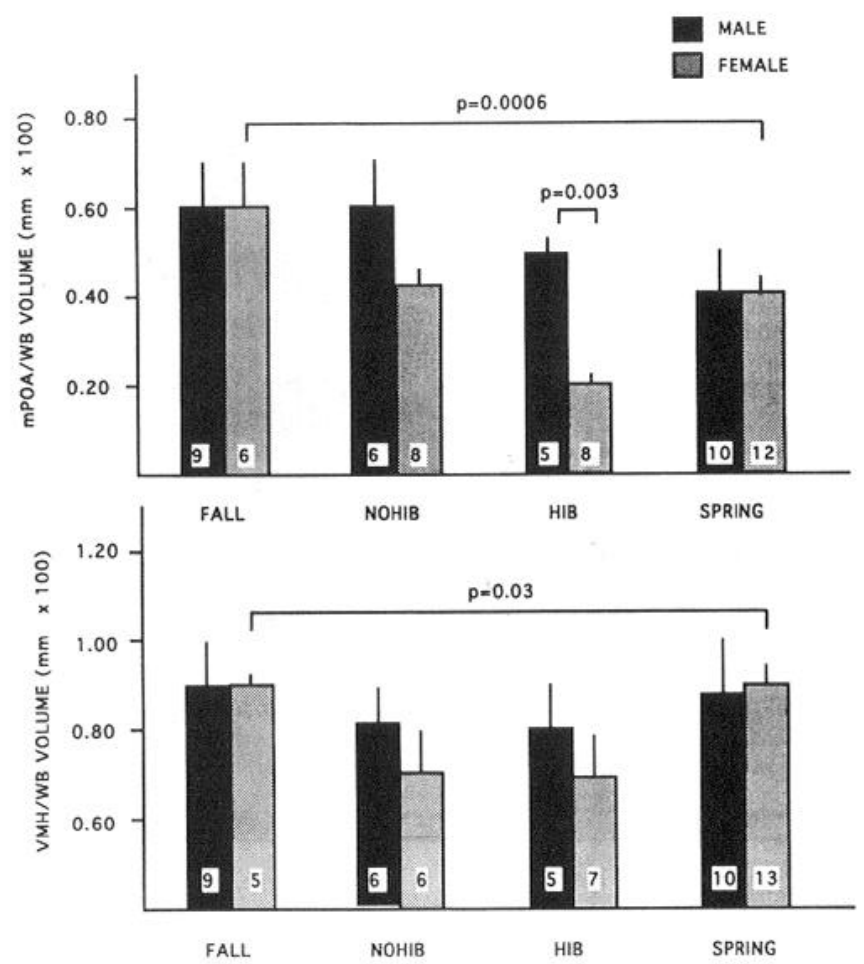

Figure 3. Average volume of POA (top) and VMH (bottom) of male and female red-sided garter snakes (Thamnophis sirtalis parietalis) at different times of year. Measurements (in $\mathrm{mm}^{3}$ ) were adjusted for whole brain size. Significant differences are marked.

Brain measurements. The brains were embedded in paraffin, sliced coronally into $25 \mu \mathrm{m}$ sections, and stained with cresyl violet. Sections were placed on glass slides in the order of sectioning from the block, so that the prepared slides could be easily scanned, left to right, enabling a view of consecutive cross sections of the brain, anterior to posterior. Each cross section examined under the microscope was projected onto a monitor and the outline of the desired nucleus traced in one hemisphere; the side measured was consistent for all nuclei in an animal. All regions of interest were measured three times by a single observer (R.R.), with the image being erased after each tracing; the average of these measurements was the value recorded. The following areas were measured: preoptic area (POA); ventromedial hypothalamus (VMH), nucleus sphericus (NS), external nucleus of the optic tract (ENOT), and the medial forebrain bundle (MFB) (Fig. 2). In a few instances (less than $5 \%$ of measures for affected individuals), measurements were not taken in certain animals because the material was not adequate (e.g., tears, folds, excessive cracking) for accurate measurement. All measurements were done without knowledge of sex, season, or manipulation.

Nuclei volumes were calculated as follows: in every third section the region of interest was encircled and the Java Image Analysis software (Jandel Scientific) was used to calculate the area. The distance between two such encircled nuclei (three section thicknesses in this case) multiplied by their calculated areas yields the volume. The consecutive volumes were summed to give the whole nucleus volume.

The POA, VMH, ENOT, and MFB were measured in every third section at a magnification of $320 \times$. POA measurements began in its most anterior portion, which usually coincided with the beginning of the third ventricle. They were then continued as the POA grew larger lateral to the ventricle, and ended once its boundary became indistinct from surrounding cells. The anterior hypothalamus in this species does not have discrete boundaries and was not measured. The VMH begins as a small, circular region at the ventral tip of the peduncle of the lateral forebrain bundle, and increases in size before becoming small and finally disappearing. The ENOT, a small, cell-rich area dorsal to the optic tract, usually appeared near the anterior end of the POA, and disappeared a few sections after the posterior end of the POA. The MFB, a fiber-rich area ventrolateral to the optic tract, appeared anterior to the optic commissure and terminated posterior to the POA.
The NS, a large, cell-poor region that is the homolog to the mammalian amygdala, was magnified $80 \times$, and the area of every sixth section was recorded. The first NS area measurement was taken as soon as its dark border became continuous, and proceeded until its end at the level of the rostral portion of the brain stem.

To provide a control for relative size across animals, a measurement was obtained for whole brain volume, at $80 \times$ and in every sixth section of one hemisphere so that the POA, VMH, ENOT, MFB, and NS volumes were then expressed as a fraction of the whole brain volume $\times 100$. Whole brain volume was defined to be the volume between the initial appearance of the anterior commissure and the posterior end of the VMH. Corrections according to body weight or snout-to-vent length yielded similar results.

Statistics. All volume measurements were divided by whole brain volumes to correct for size differences due to allometry. The subsequent ratios were ranked. Seasonal differences in size of brain nuclei within a sex were analyzed nonparametrically by means of a Kruskal-Wallis oneway analysis of variance. If the null hypothesis was rejected, a post hoc nonparametric multiple-comparison test was conducted to determine how groups varied (Conover, 1980). Comparison of differences in brain nuclei between the sexes were also analyzed nonparametrically using a Mann-Whitney $U$ test. All analyses except the nonparametric multiple comparison tests were done using the STATVIEW II microcomputer statistical program.

\section{Results}

Comparisons according to season and manipulation revealed only two instances of sexual dimorphism: the POA of females was significantly smaller than that of males during hibernation, and the NS of females was significantly smaller than that of males in those animals not subjected to hibernation. In males, there was no statistical difference in the size of the brain areas when compared either by season or by hormonal manipulation. In females, on the other hand, there were significant seasonal fluctuations in both the POA and the VMH. Estrogen manipulation induced significant changes in a manner that paralleled the seasonal fluctuations in size.

\section{Sexual dimorphism}

The POA of females was significantly smaller than that of males only during hibernation $(Z=-2.93 ; p=0.003$ ) (Fig. 3). The NS of females was significantly smaller than that of males in the NOHIB condition $(H=-2.57 ; p=0.01)$. All other comparisons of nuclei means at the different sample points did not reveal statistically significant sex differences.

\section{Seasonal fluctuations}

Males. There was no significant fluctuation among males in the different seasons in the POA $(H=5.79 ; p=0.12)$, VMH $(H=$ $1.06 ; p=0.79)$, NS $(H=6.54 ; p=0.09)$, or ENOT $(H=2.52$; $p=0.47)$. The MFB fluctuated significantly $(H=12.45 ; p=$ 0.006); specifically, the mean MFB volume of SPRING males was significantly greater than those of FALL, NOHIB, and HIB males $(p=0.05)$ (Table 1, Fig. 3).

Females. Unlike the males, there were significant seasonal differences in both the POA $(H=17.21 ; p=0.0006)$ and $\mathrm{VMH}$ $(H=9.1 ; p=0.03)$ nuclei volumes in females (Table 1, Fig. 3$)$. In each case, the values obtained for the HIB animals were significantly smaller than either the SPRING or FALL values $(p=0.05)$. The VMH values for NOHIB animals did not differ from the values obtained from HIB females. The NS and ENOT means did not vary significantly across seasons $(H=2.64, p=$ $0.45 ; H=1.27, p=0.73)$. The MFB, however, did vary $(H=$ $12.61 ; p=0.006)$, with SPRING means being, as in the case of the males, significantly greater than FALL, NOHIB, and HIB values $(p=0.05)$. 
Table 1. Average volume of brain areas/body weight $(\times 100)$ in the red-sided garter snake (Thamnophis sirtalis parietalis) at different times of the year

\begin{tabular}{llllll} 
& & \multicolumn{2}{l}{ Group } & \\
\cline { 3 - 6 } Nucleus & Sex & FALL & NOHIB & HIB & SPRING \\
\hline POA & Male & 0.55 & 0.58 & 0.45 & 0.41 \\
& Female & 0.59 & 0.44 & 0.19 & 0.43 \\
VMH & Male & 0.88 & 0.80 & 0.76 & 0.87 \\
& Female & 0.89 & 0.72 & 0.68 & 0.88 \\
NS & Male & 7.1 & 7.9 & 7.3 & 5.8 \\
& Female & 6.8 & 5.1 & 5.9 & 5.7 \\
ENOT & Male & 0.03 & 0.02 & 0.03 & 0.03 \\
& Female & 0.02 & 0.04 & 0.02 & 0.03 \\
\multirow{2}{*}{ MFB } & Male & 0.09 & 0.10 & 0.07 & 0.20 \\
& Female & 0.12 & 0.10 & 0.08 & 0.22 \\
\hline
\end{tabular}

\section{Hormonal manipulation study}

Males. There were no statistically significant differences among the measured brain areas of hormone-manipulated animals except for the VMH, where the nuclei of SHAM individuals were ranked significantly smaller than CAST and CAST $+\mathrm{T}$ individuals $(H=6.38 ; p=0.04)$ (Fig. 4).

Females. Only POA volume differed among the analyzed nuclei of treated females $(H=7.32 ; p=0.03)$ (Fig. 4). OVEX females had a significantly smaller mean POA value than either OVEX + E or SHAM females $(p=0.05)$.

\section{Discussion}

Of 60 possible comparisons of male and female red-sided garter snakes according to season and hormonal manipulation, only two dimorphisms were found to be statistically significant. This is puzzling for in all other instances where there is an absolute difference in male and female sexual behaviors, a parallel dimorphism in brain areas has been found (Nottebohm, 1981; Kelley, 1988). Even in reptiles, there is a complementary dimorphism in the POA and the VMH in male and female Cnemidophorus inornatus; the POA is larger in males while the VMH is larger in females (Crews et al., 1990).

In males, there were no statistically significant changes in the brain areas measured at different times of the year and under different experimental conditions. In the present study, all manipulated males were killed approximately 7 weeks after the end of courtship (April 25), but approximately 18 weeks before FALL males (September 10-12). At the time of death, the sham-manipulated males were undergoing testicular recrudescence. In a real sense, then, the sham-manipulated males could be considered equivalent to summer males. However, when seasonal and treated groups were compared statistically, there were virtually no significant differences in nucleus volume, regardless of time of year or experimental manipulation (POA, $H-11.86, p-$ $0.065 ; \mathrm{VMH}, H=9.26, p=0.16$; NS, $H=10.25, p=0.11$; ENOT, $H=7.61, p=0.27$ ). The single exception was in the volume of the MFB; the means for all manipulated animals did not differ significantly from the SPRING mean but did differ from values obtained for FALL, NOHIB, and HIB males.

The lack of a significant seasonal fluctuation in males was paralleled by a lack of significant differences in the brain of
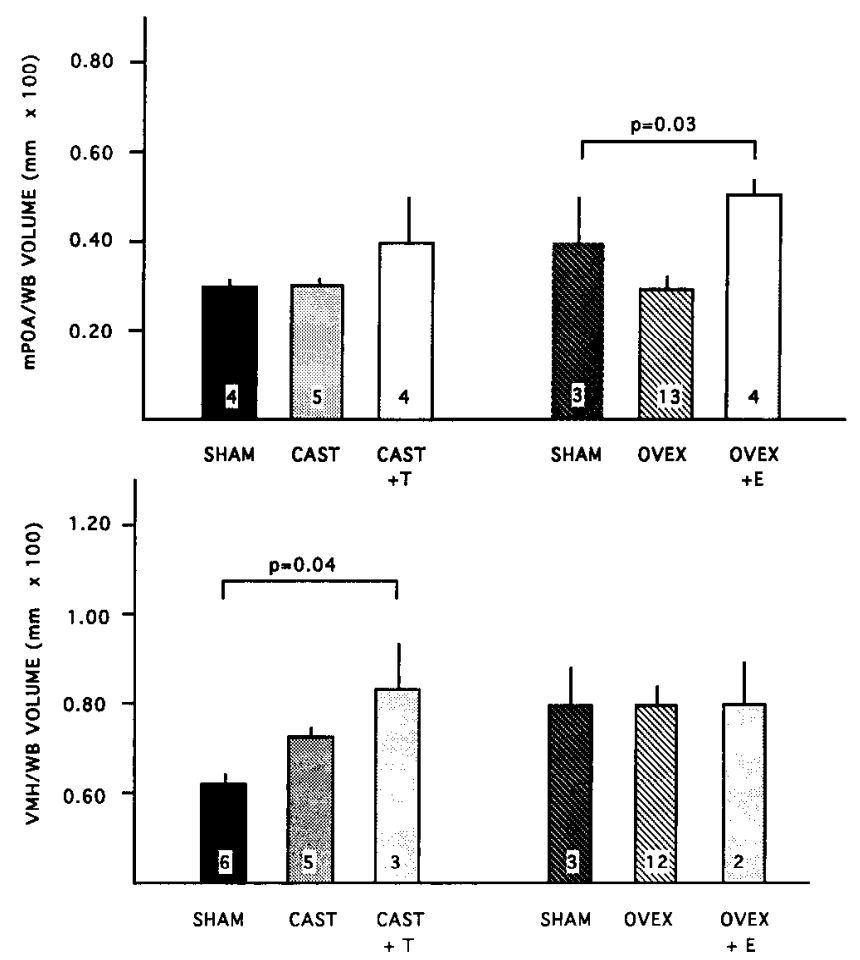

Figure 4. Average volume of POA (top) and VMH (bottom) of male and female red-sided garter snakes (Thamnophis sirtalis parietalis) that had been experimentally manipulated. Measurements (in $\mathrm{mm}^{3}$ ) adjusted for whole brain size. Significant differences are marked.

males having different hormonal manipulation. There is no cvidence to suggest that androgen or other steroid hormone is involved in the activation of sexual behavior in male red-sided garter snakes (Crews, 1990). The temperature activation of male courtship behavior, and the role of the POA in behavioral thermoregulation, suggests that this brain area is responding to an environmental cue. The fact that androgens of the previous testicular recrudescence influence courtship behavior 8 months later (Crews, 1991) suggests a functional organization without influencing limbic nucleus size.

Still, the idea that the waxing and waning in behavior is caused by the changes in the volume of brain nuclei is firmly in place. Whether this is true remains to be demonstrated convincingly. Proof would be finding consistent values in brain and behavior in the same individuals. In the whiptail lizard Cnemidophorus inornatus, the sizes of the POA and the VMH show seasonal fluctuations, but only in the male (Crews, 1991; Wade and Crews, 1991, 1992). However, there is no consistent difference in the brain areas of intact males that exhibit high-intensity courtship behavior versus those males that exhibit no courtship at all (Wade et al., 1993). Despite the many examples of parallels between the size of brain nuclei and the frequency of sexual behaviors (see introductory remarks), there are instances in which such a relationship is not found. There are no evident dimorphisms in the brain of the mouse (Young, 1982). It is perhaps significant that when some inbred strains of mice (C57BL/6 and DBA/2) are hybridized (B6D2-F1), the male sexual behavior persists following castration (McGill, 1978; Coquelin, 1991). This lack of a conventional relationship between hormone, brain, and behavior in a reptile and in a mammal suggests that the extrapolation that behavioral differences between males and 
females are the consequence of sexual dimorphisms in the brain is not warranted at this time.

The absence of any relationship between brain nucleus size and behavior in the red-sided garter snake does not mean that brain-behavior relationships at the level of the individual cannot be detected. Individual variation in brain metabolism as measured by 2-deoxyglucose utilization correlates well with the level of sexual activity exhibited by male red-sided garter snakes (Allen and Crews, 1992); perhaps significantly, males with greater 2-deoxyglucose utilization in limbic nuclei tended to be courters. Gahr (1990) demonstrated that in the canary, seasonal fluctuations in Nissl staining are not correlated with the patterns of immunoreactivity using the estrogen receptor antibody $\mathrm{H} 222$. Taken together, these data support the interpretation that brainbehavior correlations may be better marked by activity changes rather than by volumetric changes.

Female red-sided garter snakes did undergo dramatic changes in the volume of brain nuclei. This finding is in contrast with the current literature, which indicates that in vertebrates, fluctuations in nucleus size usually are restricted to the male. In the present study the most robust seasonal difference in nucleus size was the dramatic decrease in the volume of the POA of females in hibernation. POA volume was reduced $66 \%$ in the 8 week interval between the FALL sample and the HIB sample. What is even more remarkable is the significant difference between the HIB and SPRING values. The females of the SPRING sample had been collected from mating balls (see Fig. 1, bottom) and are presumed to have recently emerged from the underground hibernaculum; most females do not remain at the den site after emergence (Garstka et al., 1982). The HIB females were killed halfway through hibernation; this length of time in low-temperature dormancy is sufficient to induce attractivity (Whittier et al., 1987b). It may be important to note that although receptive animals presumably are always attractive, attractive animals are not always receptive (Crews, 1990).

If the HIB animals are a true indicator of the neural state of animals throughout natural hibernation, then there appears to be a rapid and substantial increase in POA volume on emergence, an interval that normally encompasses minutes or hours. The temperature range that stimulates females to emerge elicits a logarithmic $Q_{10}$ response of 8 in standard metabolic activity rather than the standard $Q_{10}$ of 2 or less in the normal activity range (Aleksiuk, 1976). This temperature compensation allows these reptiles to have extremely high rates of protein synthesis at temperatures that normally are not thought to allow this. A slight increase in temperature at this range causes an eightfold shift. This response may cause an increase in neuronal estrogen receptor activity, thus increasing protein synthesis and allowing for rapid change in volumetric area. Consistent with this hypothesis is that a greater number of brain cells immunoreactive to the $\mathrm{H} 222$ estrogen receptor antibody are found $1-4 \mathrm{hr}$ after emergence from hibernation compared to $1 \mathrm{~d}$ before emergence (M. Gahr, M. Mendonça, and D. Crews, unpublished observations). Alternatively, there may be a gradual increase in the POA during the latter half of hibernation (an interval we did not sample) and the change may not be as dramatic as it appears.

The seasonal decrease of nuclei volume in females becomes even more important when viewed in the context of sexually dimorphic nuclei. The POA is the only area that was sexually dimorphic, but only when compared between hibernating animals. In other words, while the POA of the male remained constant year-round, the POA of the female decreased precip- itously in hibernation but then regained its previous dimensions upon warming. It should also be noted that there was a decrease in the POA of NOHIB females, but it was not significant statistically. This seasonal decline, regardless of ambient condition (i.e., $24^{\circ} \mathrm{C}$ vs $4^{\circ} \mathrm{C}$ for 8 weeks), may be an important trend. While the $\mathrm{VMH}$ of nonhibernating and hibernating females did not differ from each other, they were significantly smaller than those of FALL or SPRING animals. An equivalent decline did not occur in either the NS, the ENOT, or the MFB. In fact, the MFB did not differ across seasons except in the SPRING females, where it was significantly larger-in exactly the same manner and magnitude as it did in males. Again, it is not clear why the MFB should change. It is unlikely that new nerve fibers would grow in the short time span. However, it should be noted that the MFB contains the processes of many serotonergic and adrenergic neurons (Feldman and Quenzer, 1984; Bradford, 1986) and these neurotransmitters have an effect on receptivity of females (M. Mendonça and D. Crews, unpublished observations).

Also unlike males, the differences in brain volumetrics among manipulated females were consistent with a causal interpretation. The POA was the only nucleus to change in response to steroid treatment. Ovariectomized females treated with estradiol had significantly larger POA volumes than did vehicletreated ovariectomized females, but they not differ from shammanipulated females. Although caution must be used because sample sizes of the OVEX $+\mathrm{E}$ and SHAM animals are low ( $n$ values of 4 and 3), the comparison between $\operatorname{OVEX}(n=13)$ and OVEX $+\mathrm{E}(n=4)$ is robust $(Z=-2.15 ; p=0.01)$ and confirms that ovariectomy had an effect of POA size. Preliminary studies indicate the lesions in the POA of females abolish receptivity (Mendonça and Crews, unpublished observations). It is important to note that the ovariectomized, estrogen-treated females had received a single injection of estradiol at emergence (see Mendonça and Crews, 1993, for further details). Females whose ovaries were removed prior to hibernation and had no detectable (via radioimmunoassay) estradiol in the circulation at the time of emergence will not be receptive to male courtship (Mendonça and Crews, 1993). However, intact females have low but detectable circulating concentrations of estradiol during hibernation and at the time of emergence. Thus, it appears that, unlike males, the female red-sided garter snake is dependent on sex steroids for the activation of sexual behavior.

One source of the endogenous estrogen is the ovary. The histological condition of the ovaries at this time shows that they contain only previtellogenic follicles (Halpert et al., 1982). Alternatively, the estrogen could emanate from the brain. The brain of the male zebra finch synthesizes estradiol from androgen and releases this estrogen into the blood (Schlinger and Arnold, 1992). This neural estrogen thus can serve a paracrine or autocrine function rather than the classical endocrine role. A similar phenomenon occurs with oxytocin and the regulation of parturition (Lefebvre et al., 1992).

It is perhaps significant that estrogen activation of receptivity in ovariectomized females is only accomplished if the hormone is given immediately prior to emergence, before the female has raised her body temperature to ambient conditions. If estrogen is administered even a few hours after emergence, it is not as effective in inducing receptivity (Mendonça and Crews, 1993). Taken together, the action of estrogen both is rapid (measured in minutes) and has but a brief window of sensitivity. This dynamic suggests the estrogen effect is mediated by a membrane- 
bound estrogen receptor (McEwen, 1991). The change in the size of brain nuclei also would suggest that such membranemediated actions can, along with the classical genomic effects of estrogen, promote new neuronal growth to modulate behavior.

Females collected within a few hours of emergence had brain areas the size of females prior to entering hibernation. This relationship was robust even after the values were corrected for body size. One possibility is that the overall brain size shrinks during hibernation, yet the nuclei remain constant. In the garter snake, the whole brain:body size ratio shows no significant difference among seasons, nor do the ratios of structure:MFB and structure:ENOT.

It would be incorrect to presume that the observed change in size of the POA must have an influence on receptivity. This could bc just a correlation without any causative effect. However, if this decrease in POA volume is just an effect of temperature, why then is it not seen in the males? Recall that in males there was no seasonal difference in any of the nuclei (though the MFB varied in the same manner as in females). In addition, if this decrease is just a manifestation of minimal metabolic activity, why did the other nuclei measured not show an equivalent decrease? Therefore, although it is not clear whether the decrease in POA size, and even more importantly, the apparent increase in size upon emergence, has an effect on sexual behavior in females, it does appear to be a response to the circulating estrogen. Estradiol naturally is present in approximately $50-1000 \mathrm{pg} / \mathrm{ml}$ levels in hibernating females, but there would be little if any metabolic processing of this estrogen during hibernation (Crews, unpublished observations); with the probable exception of cold-adapted poikilotherms, at $4^{\circ} \mathrm{C}$ any steroid hormone is physiologically inert (Licht, 1986). Upon emergence, however, metabolic activity resumes and this estrogen could suddenly become available to the neurons of the POA. It is tempting to speculate that this estrogen acts in the POA to increase cell activity and/or size to modulate female sexual receptivity.

\section{References}

Aleksiuk M (1976) Metabolic and behavioral adjustments to temperature change in the red-sided garter snake Thamnophis sirtalis parietalis: an integrated approach. J Thermal Biol 1:153-156.

Allen EE, Crews D (1992) Sexual behavior and 2-deoxyglucose uptake in male red-sided garter snakes (Thamnophis sirtalis parietalis). Brain Behav Evol 40:17-24.

Bloch GJ, Gorski RA (1988) Estrogen/progesterone treatment in adulthood affects the size of several components of the medial preoptic area in the male rat. J Comp Neurol 275:613-622.

Bona Gallo A, Licht P (1983) Effects of temperature on sexual receptivity and ovarian recrudescence in the garter snake, Thamnophis sirtalis parietalis. Herpetologica 39:173-182.

Bradford HF (1986) Chemical neurobiology. New York: Freeman.

Conover WJ (1980) Practical non-parametric statistics. New York: Wiley.

Coquelin A (1991) Persistent sexual behavior in castrated, recombinant inbred mice. Biol Reprod 45:680-684.

Crews D (1983) Control of male sexual behavior in the Canadian redsided garter snake. In: Hormones and behavior in higher vertebrates (Balthazart J, Prove E, Gilles R, eds), pp 398-406. London: Plenum.

Crews D (1984) Gamete production, sex hormone secretion, and mating behavior uncoupled. Horm Behav 18:22-28.

Crews D (1990) Neuroendocrine adaptations. In: Hormones, brain and behaviour in vertebrates (Balthazart J, ed), pp 1-14. Basel: Karger.

Crews D (1991) Trans-seasonal action of androgen in the control of spring courtship behavior in male red-sided garter snakes. Proc Natl Acad Sci USA 88:3545-3548.

Crews D, Silver R (1985) Reproductive physiology and behavior interactions in nonmammalian vertebrates. In: Handbook of behavioral neurobiology (Adler NT, Pfaff DW, Goy RW, eds), pp 101-182. New York: Plenum.

Crews D, Wade J, Wilczynski W (1990) Sexually dimorphic areas in the brain of whiptail lizards. Brain Behav Evol 36:262-270.

Dohler KD, Coquelin A, Davis F, Hines M, Shryne JE, Gorski RA (1984) Pre- and postnatal influence of testosterone propionate and diethylstilbestrol on differentiation of the sexually dimorphic nucleus of the preoptic area of male and female rats. Brain Res 302:291-295.

Feldman RS, Quenzer LF (1984) Fundamentals of neuropsychopharmacology. Sunderland, MA: Sinauer.

Friedman DW, Crews D (1985) Role of the anterior hypothalamuspreoptic area in the regulation of courtship behavior in the male Canadian red-sided garter snake (Thamnophis sirtalis parietalis): lesion experiments. Behav Neurosci 99:942-949.

Gahr M (1990) Delineation of a brain nucleus: comparisons of cytochemical, hodological, and cytoarchitectural views of the song control nucleus HVC of the adult canary. J Comp Neurol 294:30-36.

Garstka WR, Camazine B, Crews D (1982) Interactions of behavior and physiology during the annual reproductive cycle of the red-sided garter snake, Thamnophis sirtalis parietalis. Herpetologica 38:104123.

Garstka WR, Tokarz RR, Diamond M, Halpert A, Crews D (1985) Behavioral and physiological control of yolk synthesis and deposition in the female red-sided garter snake Thamnophis sirtalis parietalis. Horm Behav 19:137-153.

Halpern M (1992) Nasal chemical senses in reptiles: structure and function. In: Hormones, brain, and behavior: biology of the reptilia (Gans C, Crews D, eds), pp 423-523. Chicago: University of Chicago.

Halpern M, Morrell J, Pfaff D (1982) Cellular $\left[{ }^{3} \mathrm{H}\right]$ estradiol and $\left[{ }^{3} \mathrm{H}\right]$ testosterone localization in the brain of garter snakes: an autoradiographic study. Gen Comp Neurol 46:211-224.

I Ialpert A, Garstka W, Crews D (1982) Sperm transport and storage and its relation to the annual sexual cycle of the female red-sided garter snake, Thamnophis sirtalis parietalis. J Morphol 174:149-159.

Ingle D, Crews D (1985) Vertebrate neuroethology: definitions and paradigms. Annu Rev Neurosci 8:457-494.

Kelley DB (1988) Sexually dimorphic behaviors. Annu Rev Neurosci 10:225-252.

Krohmer RW, Crews D (1987a) Temperature activation of courtship behavior in the male red-sided garter snake (Thamnophis sirtalis parietalis): role of the anterior hypothalamus-preoptic area. Behav Neurosci 101:228-236.

Krohmer RW, Crews D (1987b) Facilitation of courtship behavior in the male red-sided garter snake (Thamnophis sirtalis parietalis) following lesions of the septum or nucleus sphericus. Physiol Behav 40: 759-765.

Lefebvre DL, Giaid A, Bennett H, Larivière R, Zingg HR (1992) Oxytocin gene expression in rat uterus. Science 256:1553-1555.

Licht $P$ (1986) Suitability of the mammalian model in comparative reproductive endocrinology. In: Comparative endocrinology: developments and directions (Ralph CL, ed), pp 95-114. New York: Liss.

Mason RT, Fales HM, Jones TH, Pannell LK, Chinn JW, Crews D (1989) Sex pheromones in garter snakes. Science 245:290-293.

McEwen BS (1991) Non-genomic and genomic effects of stcroids on neural activity. Trends Pharmacol Sci 12:141-147.

McGill TE (1978) Genotype-hormone interactions. In: Sex and behavior (McGill TE, Dewsbury DA, Sachs BD, eds), pp 161-187. New York: Plenum.

Mendonça MT, Crews D (1990a) Mating-induced ovarian recrudescence in the red-sided garter snake. J Comp Physiol 166:629-632.

Mendonça MT, Crews D (1990b) Effects of ovariectomy and estrogen replacement in the garter snake, Thamnophis sirtalis parietalis. Am Zool 30:53A.

Mendonça MT, Crews D (1993) Effects of ovariectomy and estrogen replacement on attractivity and receptivity in a dissociated pattern breeder, the red-sided garter snake (Thamnophis sirtalis parietalis). J Comp Physiol, submitted.

Noble GK (1937) The sense organs involved in the courtship of Storeria, Thamnophis and other snakes. Bull Am Nat Hist 73:673-725.

Nottebohm F (1981) A brain for all seasons: cyclical anatomical changes in song control nuclei of the canary brain. Science 214:1368-1370. 
Panzica G, Viglietti-Panzica C, Sanchez F, Sante P, Balthazart J (1991) Effects of testosterone on a selected neuronal population within the preoptic sexually dimorphic nucleus of the Japanese quail. J Comp Neurol 303:443-456.

Ross P, Crews D (1977) Influence of the seminal plug on mating behavior in the garter snake. Nature 267:344-345.

Ross P Jr, Crews D (1978) Stimuli influencing mating behavior in the garter snake, Thamnophis radix. Behav Ecol Sociobiol 4:133-142.

Schlinger BA, Arnold AP (1992) Circulating estrogens in a male songbird originate in the brain. Proc Natl Acad Sci USA 89:7650-7653.

Tobet SA, Zahniser DJ, Baum MJ (1986) Differentiation in male ferrets of a sexually dimorphic nucleus in the preoptic/anterior hypothalamic area requires prenatal estrogen. Neuroendocrinology 44 : 299-308.

Ulibarri C, Yahr P (1988) Role of androgens in sexual differentiation of brain structure, scent marking, and gonadotropin secretion in gerbils. Behav Neural Biol 49:27-44.

Wade J, Crews D (1991) The relationship between reproductive state and "sexually" dimorphic brain areas in sexually reproducing and parthenogenetic whiptail lizards. J Comp Neurol 309:507-514.

Wade J, Crews D (1992) Sexual dimorphisms in the soma size of neurons in the brain of whiptail lizards (Cnemidophorus species). Brain Res 594:311-314.
Wade J, Huang J-M, Crews D (1993) Hormonal control of sex differences in the brain, behavior, and accessory sex structures of whiptail lizards (Cnemidophorus species). J Neuroendocrinol 5:81-93.

Whittier JM, Crews D (1986) Ovarian development in red-sided garter snakes, Thamnophis sirtalis parietalis: relationship to mating. Gen Comp Endocrinol 61:5-12.

Whittier JM, Crews D (1989) Mating increases plasma levels of prostaglandin F2a in female garter snakes. Prostaglandins 37:359-366.

Whittier JM, Crews D (1990) Body mass and reproduction in female red-sided garter snakes (Thamnophis sirtalis parietalis). Herpetologica 46:219-226.

Whittier JM, Mason RT, Crews D (1985) Mating in the red-sided garter snake, Thamnophis sirtalis parietalis. Differential effects on malc and femalc scxual bchavior. Behav Ecol Sociobiol 16:257-261.

Whittier JM, Mason RT, Crews D (1987a) Plasma steroid hormone levels of female red-sided garter snakes, Thamnophis sirtalis parietalis: relationship to mating and gestation. Gen Comp Endocrinol 67: 33-43.

Whittier JM, Mason RT, Crews D, Licht P (1987b) Role of light and temperature in the regulation of reproduction in the red-sided garter snake, Thamnophis sirtalis parietalis. Can J Zool 65:2090-2096.

Young JK (1982) A comparison of hypothalami of rats and mice: lack of gross sexual dimorphism in the mouse. Brain Res 239:233-239. 